\title{
Fragile (X)(q27) sites in a pedigree with female carriers showing mild to severe mental retardation
}

\author{
G C WEBB*, J L HALLIDAY $\dagger$, D B PITT $\dagger$, C G JUDGE $\ddagger$, AND M LEVERSHA*
}

From *the Department of Genetics and $\dagger$ the Department of Paediatrics, Royal Children's Hospital, Parkville, Victoria 3052; and $†$ St Nicholas Hospital, Carlton, Victoria 3053, Australia.

SUMMARY A pedigree showing the fragile site at Xq27 in a severely retarded female and in othep less retarded carriers is described. Two of the four moderately retarded males with the fra(X)(q27) show macro-orchidism, and a variety of other features usually used to support the effects of the fra(X)(q27) are also inconsistent. A second fragile site at (10)(q23) is also present and in the two oldes $\vec{\oplus}$ females its frequency is not decreased, whereas the fra $(X)(q 27)$ is not detectable in these females although probably present. It is concluded that pedigrees showing mentally retarded females and probable X linkage should be included in studies of the fra(X)(q27).

The development of the topic of fragile (X)(q27) sites and associated $X$ linked mental retardation has recently been well summarised by Gerald. ${ }^{3}$ Recently, interest has shifted from affected males to the effect of the fra(X)(q27) in heterozygous females who may be normal or 'dull', but it has been suggested that about 20 to $30 \%$ of carriers are clinically detectable as retarded. ${ }^{2}$

We report a family (fig 1 ) which was initially excluded from a study of fra(X)(q27) because it showed some mentally retarded females and so did Received for publication 6 March 1981 not conform to a recessive mode of $X$ linked inheritance. However, the proband showed macro $\overrightarrow{0}$ orchidism which has been strongly associated with the $\operatorname{fra}(\mathrm{X})(\mathrm{q} 27)$ by some authors, ${ }^{3-6}$ but not by others. ${ }^{7}$ On investigation the pedigree was found to involve both the $\mathrm{fra}(\mathrm{X})(\mathrm{q} 27)$ and the fra(10)(q23) sites.

\section{Methods}

For the subjects in this family it was not possible to measure mental abilities in a uniform fashion becaus

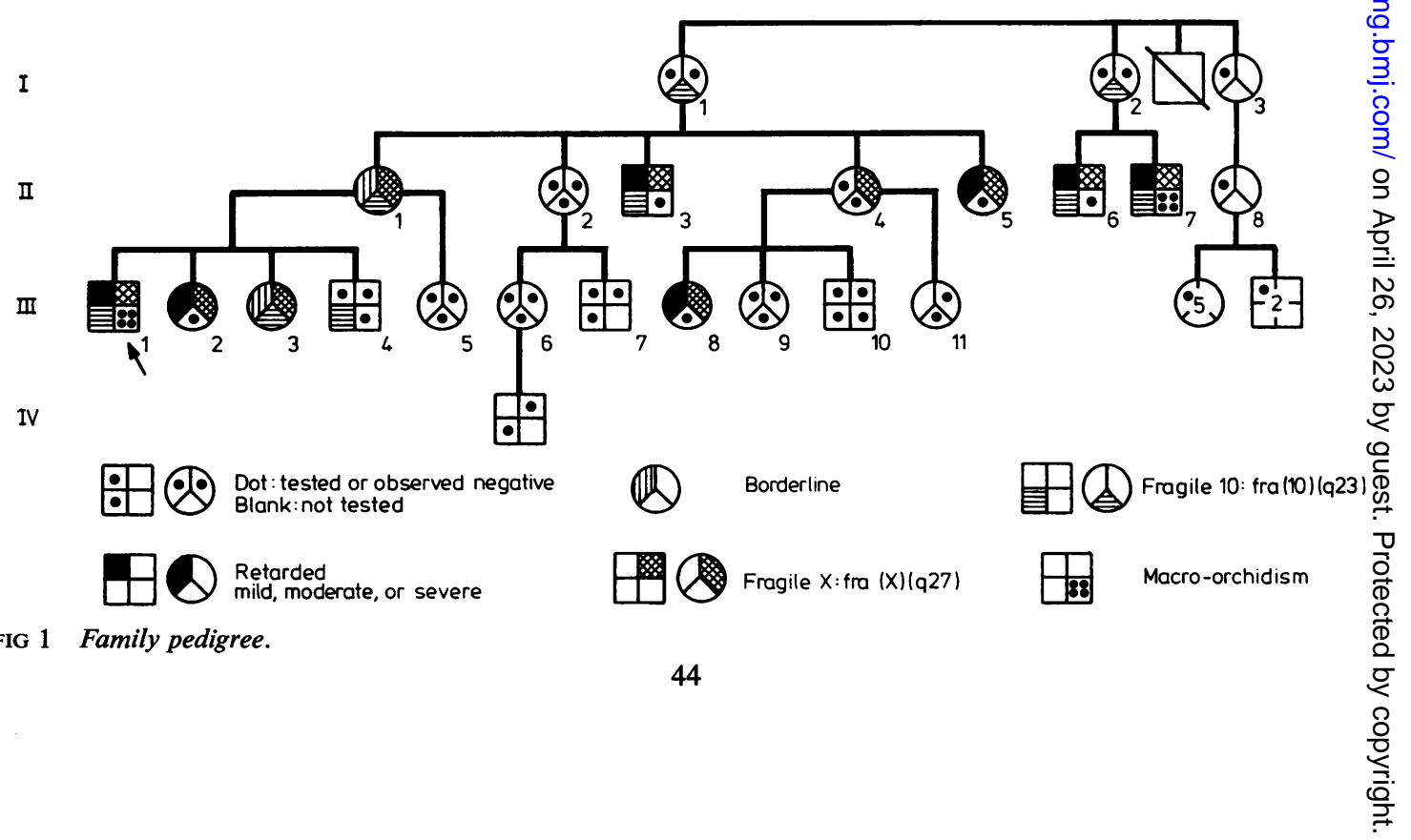


the members are widely dispersed, with retarded members in a variety of institutions. Because of this, retarded subjects are largely classified on the basis of clinical assessment, supported by psychological testing in certain critical cases. The classification of retardation is that of the World Health Organization ${ }^{8}$ with IQ ranges: mild $50-70$, moderate $35-49$, severe 20-34, and profound 0-19.

For chromosome studies whole blood was cultured in TC 199 using methods which are well documented for the detection of fragile sites. ${ }^{9}$ Initially, $5 \%$ calf serum was used but an increase to $14 \%$ was found to give an improved yield of metaphases without affecting the frequency of fragile sites.

A minimum of 50 metaphase plates were analysed for each patient, with more cells analysed to confirm low or zero scores. Apart from two cases investigated early in the study all cases were scored from G banded slides following the discovery of a lesion at $6 \mathrm{q} 26$ which looked very similar to the $\mathrm{fra}(\mathrm{X})(\mathrm{q} 27)$ in plain stained preparations. ${ }^{10}$ In some cases both methods were used.

The normal testes of two of the mentally retarded males were measured with an orchidometer. In the two mentally retarded males with macro-orchidism the testicular volumes were calculated from the length (l) and width (w): the volume being $\pi \mathrm{lw}^{2} / 6{ }^{11}$ The two males with macro-orchidism had mean testicular volumes well in excess of $23 \mathrm{ml}$ (90th centile). ${ }^{3}$

\section{Results}

MALES WITH fra(X)(q27)

All four males with the fra(X)(q27) also carry the fra(10)(q23) and they are all assessed as being in the lower range of moderate mental retardation.

The proband (III 1 ) and his maternal uncle (II $\cdot 3$ ) have similar unusual facies with a prominent mandible, long narrow face, broad solid nose, and large ears (figs 2, 3). Individual unusual
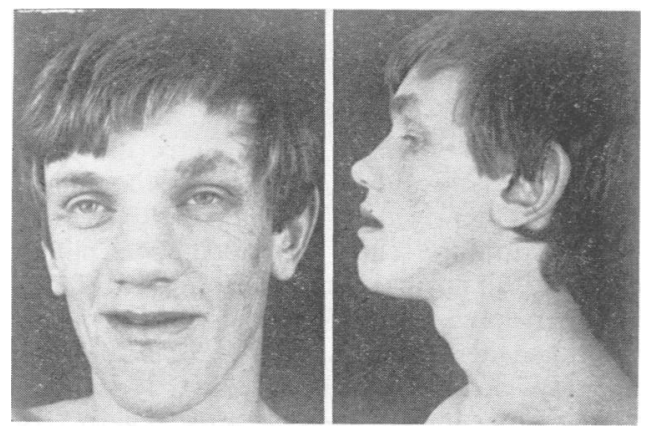

FIG 2 The proband III $\cdot 1$.

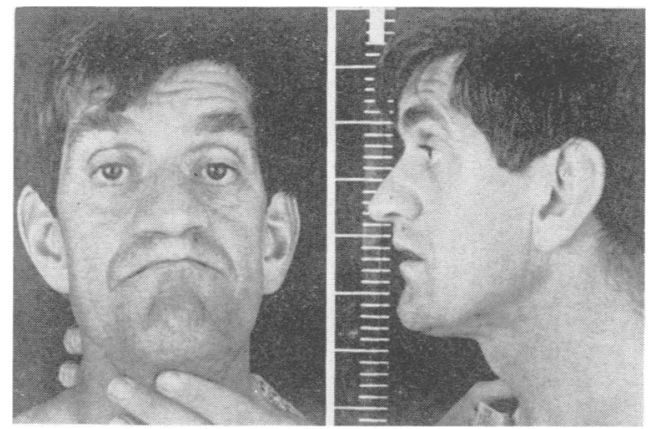

FIG 3 Male $I I \cdot 3$.

characteristics of III 1 include bright blue irides, rather hyperkeratotic skin with an unusual rash across the cheeks, nose, and chin, and pes planus. II.3 has hazel eyes, brachycephaly, and hepatomegaly. However, the most striking difference between these two males is the size of the testes: III 1 has macro-orchidism, whereas II 3 has testes with a normal volume (table).

The two brothers II $\cdot 6$ and II $\cdot 7$ also show a marked difference in testis size: II 6 has normal testes and II. 7 shows extreme macro-orchidism (table). II 6 (fig 4) is quite unlike II.3 and III.1. He has a long narrow face with a normal chin, large ears with unrolled helices, and an antimongoloid slant to his brown eyes. He shows mild gynaecomastia and has received hormone treatment, but his testes, penis, beard, and pubic hair are normal. II.7 has not been seen by us but has been examined at our request. He has brown eyes, normal chin, no gynaecomastia, and large ears (75 $\mathrm{mm}$ long).

MALES Without THE fra(X)(q27)

The intellectual normality of these males is indicated by their normal progress in school and in some cases

TABLE Frequencies of the $f r a(X)(q 27)$ and $f r a(10)(q 23)$ sites

\begin{tabular}{llllll}
\hline Person & Sex & $\begin{array}{c}\text { Year of } \\
\text { birth }\end{array}$ & $\begin{array}{l}f r a(X)(q 27) \\
(\%)\end{array}$ & $\begin{array}{l}f r a(10)(q 23) \\
(\%)\end{array}$ & $\begin{array}{l}\text { Mean testis } \\
\text { volume }(\mathrm{ml})\end{array}$ \\
\hline I.1 & F & 1903 & 0 & 19 & \\
I.2 & F & 1905 & 0 & 15 & \\
II.1 & F & 1934 & $12^{*}, 6$ & $18^{*}, 15$ & \\
II.3 & M & 1940 & 52 & 34 & 17.5 \\
II.4 & F & 1943 & 32 & 0 & \\
II.5 & F & 1945 & 42 & 0 & \\
II.6 & M & 1942 & 6 & 17 & 20 \\
II.7 & M & 1945 & 14 & 20 & 71 \\
III.1 & M & 1959 & 35 & 27 & 59 \\
III.2 & F & 1960 & 34 & 0 & \\
III.3 & F & 1965 & $18^{*}, 19$ & $10 *, 11$ & \\
III.4 & M & 1970 & 0 & 18 & \\
III.8 & F & 1962 & 46 & 0 & \\
\hline
\end{tabular}

*Percentages derived from plain stained preparations. 


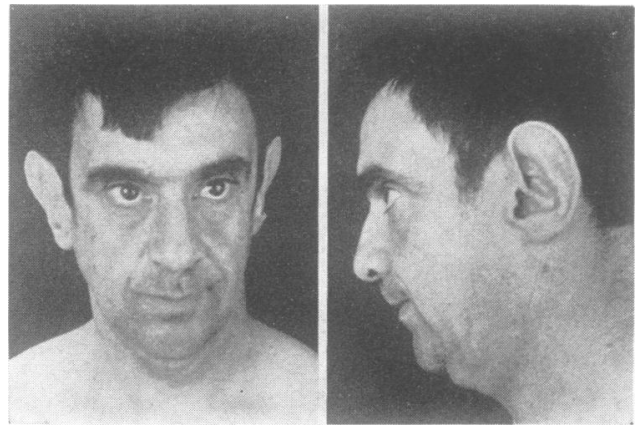

FIG 4 Male $I I \cdot 6$.

by clinical assessment. IV 1 is only 6 months old but is developing normally. The male in generation I was intellectually normal and died aged 68 . Only one normal male is carrying the fra(10)(q23). The rest of them are not at risk for inheritance of this fragile site.

RETARDED FEMALES WITH THE fra(X)(q27)

There is a large range of mental abilities in females in the pedigree who carry the fra(X)(q27). The most retarded carrier is II.5 (fig 5) who is functioning intellectually at the lower limits of severe mental retardation as assessed clinically and psychologically (IQ less than 30, mental age 3.5 years). She is emotionally disturbed and cries easily. She has few self-help skills, poor personal hygiene, a short attention span, and is capable of only simple tasks. She has similar facies to her brother II $\cdot 3$, with hazel eyes, a very prominent jaw, and broad nose. Characteristics which are not shared with her brother include a divergent squint, poor teeth, and mild obesity. Along with three of five members of her sibship, II 5 has not inherited the fra(10)(q23) from her mother.

III. 2 (fig 6 ) is regarded as physically very similar

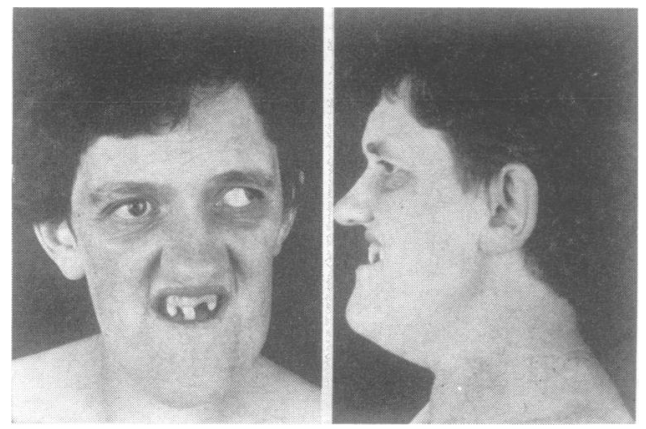

FIG 5 Female II 5.
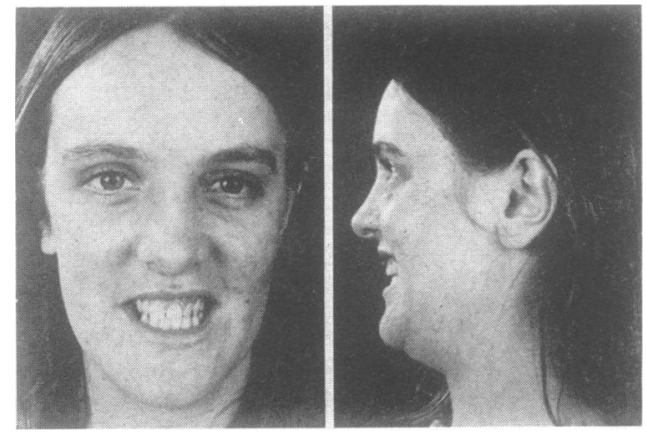

FIG 6 Female $I I I \cdot 2$.

to her aunt II.5. However, psychological testinggave a result in the upper moderate range. She is not permanently confined but works in a shelteredo environment. She speaks in short sentences and cries readily. During psychological testing she was notablyp shy, embarrassed, and distracted by the male assessor $\stackrel{\mathbb{O}}{-}$ She has a prominent jaw and bright blue irides like her brother III $\cdot 1$, and she has a high arched palate but no other dysmorphic features. She is mildly obese $\vec{\imath}$

III. 8 has a very prominent jaw and shows similarop shy and embarrassed behaviour to her cousin III $\cdot 2^{2}$ She has been psychologically assessed as mildlyo retarded. She reached middle secondary school ands will probably gain employment in a shelteredo environment. This girl had fra(X)(q27) sites visible in $46 \%$ of her lymphocytes, slightly higher than hep aunt II. 5 (table). These are the highest frequencies $\vec{B}$ yet recorded in carriers, the next highest frequency 3 being $38 \%{ }^{5}$

OTHER FEMALE CARRIERS OF THE fra(X)(q27)

It is likely that all but one of the carrier females in this pedigree have some intellectual impairment, probably resulting from the fra(X)(q27). III.3 has blue eyes and a prominent jaw. She has an arched palate but no other dysmorphic features. She was clinically assessed as dull normal-mildly retarded (borderline). Her own doctor describes her as highlys emotional. She reached middle secondary school with? difficulty and her part-time employment involves simple work.

The carrier mothers in the pedigree are socially 0 well adjusted and some of them are coping with economically deprived situations. II 11 only reachedb the end of primary schooling and she was clinically assessed as dull normal-mildly retarded at the same्ष time as her daughter III · 3 . Her sister II 4 was more? successful in her schooling but is described by the family physician as slower than II 1 . However, foo want of further information we must regard II. 4 a\$ dull normal. 
The intellectual capacity of $I \cdot 1$ is regarded as difficult to assess by her family physician, who has known her for only 12 months. This is because of age-related physical deterioration. However, her normal daughter (II-2) gave a description of her mental capacities at a younger age which indicates that she was at least mentally normal and probably better than average. I 2 has been known to her family physician for 30 years and is regarded by the doctor and by her normal niece as intellectually dull. It is interesting to note that in these old sisters the fra(X)(q27) cannot be detected, although it must be presumed present. However, the frequency of the fra(10)(q23) is not affected by their age (table). Turner et $a l^{5}$ found the fra(X)(q27) in $2 \%$ of cells in a 65-year-old obligate carrier, the oldest female to show the site, but it is often not detectable in obligate carriers at a much younger age. Therefore, it is unlikely that the fra $(X)(q 27)$ could be detected in I 3 . For social reasons $\mathrm{I} \cdot 3$ and her family cannot be tested.

FEMALES Without THE fra(X)(q27)

These are all normal. III 2 is less than 2 years old but she has reached her milestones at expected ages. The evidence on the normality of the family of $I \cdot 3$ is heresay but it is on reasonable grounds.

\section{Discussion}

The most important result in this investigation was the finding of a range of intellectual capacity in female carriers of the fra(X)(q27) with the most extreme being severely retarded. In previous investigations, female carriers of the $\mathrm{fra}(\mathrm{X})(\mathrm{q} 27)$ have been reported with degrees of retardation up to the mild level (Turner $e t a^{2}$ and other papers listed by them). The Lyon hypothesis has been used to explain a range of retardation in carriers of the fra(X)(q27). ${ }^{12}$ Gerald $^{1}$ suggested that the severity of expression of mental retardation in these females might depend directly on the proportion of cells which by chance have the normal $X$ inactivated in tissues critical to intellectual capacity. The finding of a severely retarded carrier is compatible with this argument and suggests that in such a case the relevant tissues might have a preponderance of cells with the normal $X$ inactive and the $\operatorname{fra}(X)(q 27)$ active. The alternative extreme, with most cells having the normal $X$ active in critical tissues, should pertain in carriers who are normal. These carriers might even have greater than average intelligence and $I \cdot 1$ could be in this category.

Another hypothesis, put forward by Gerald, ${ }^{1}$ is that carrier mothers of affected sons with the fra(X)(q27) represent a population selected for their closeness to intellectual normality. Superficially our results appear to agree with this hypothesis but there is no reason to suppose that III $\cdot 2$, III $\cdot 3$, and III $\cdot 8$ could not bear children.

It is clear that the presence of retarded females in a pedigree should no longer be taken as a reason for not searching for the fra(X)(q27) in retarded males and their female relatives. What is not clear is a set of indications which will always lead to detection of the $\operatorname{fra}(X)(q 27)$.

Although macro-orchidism initially led us to this family, normal sized testes were also found in males with the $\operatorname{fra}(X)(q 27)$. Furthermore, this variation was observed within one sibship. Another such finding was family $\mathrm{A}$ in the report of Harvey et $a l^{12}$ after later measurement of some of the testicular volumes by Sutherland et al. ${ }^{6}$ Four of the six mentally retarded males with the fra(X)(q27) in this family were measured, three showed macroorchidism, and one had normal testicular volumes. Sutherland and Ashforth ${ }^{3}$ described a solitary 65-year-old male with fra(X)(q27) and small (12.5 $\mathrm{ml}$ ) testes, who was the only post-pubertal male who did not have macro-orchidism in a sample of males with the fra $(\mathrm{X})(\mathrm{q} 27)$. Testicular atrophy was suggested in this male by Sutherland and Ashforth, but a drastic reduction in size must have taken place if this male showed macro-orchidism at a younger age. While macro-orchidism is probably common among males with the $\mathrm{fra}(\mathrm{X})(\mathrm{q} 27)$, the finding of normal testis volumes among such males may not be rare, as illustrated in the pedigree we have described. Indeed, of six families with pedigrees of $\mathrm{X}$ linked mental retardation described by Jacobs et $a l,{ }^{7}$ three showed the fra(X)(q27) and no macroorchidism, one had no $\operatorname{fra}(\mathrm{X})(\mathrm{q} 27)$ but showed macro-orchidism, and the remaining two had neither $\mathrm{fra}(\mathrm{X})(\mathrm{q} 27)$ nor macro-orchidism. It does appear that there is a relationship between macro-orchidism, fra(X)(q27), and mental retardation, but elucidation of the exact interrelationship of the factors concerned will probably require much more information from pedigrees.

Pale blue irides are not seen in all males and females with the fra(X)(q27) in our pedigree, although in the index case they were seen as a supportive feature. In the affected members of the pedigree with hazel and brown eyes, genes for brown irides appear to be dominant to blue eyes. Mild gynaecomastia has been previously reported in some mentally retarded males with macro-orchidism who by now might have been analysed for $\mathrm{fra}(\mathrm{X})(\mathrm{q} 27){ }^{1314}$ However, II. 6 is the first male reported with the combination of gynaecomastia, fra(X)(q27), mental retardation, and normal testes. In the same male the 
usual prominence of the jaw is absent. In one girl (III.9) without the $\operatorname{fra}(\mathrm{X})(\mathrm{q} 27)$, a prominent jaw was noted so this feature might be under some familial influence in this pedigree.

The variability of males and females carrying the fra(X)(q27) supports the recommendation that a medium suitable for demonstration of fragile sites should be routinely used in diagnostic laboratories (Sutherland editorially supported by Hecht and Kaiser-McCaw $\left.{ }^{9}{ }^{15}\right)$. The finding of $\mathrm{fra}(\mathrm{X})(\mathrm{q} 27)$ may be an unexpected result in cases of mental retardation. For example, in our laboratory we have detected the fra(X)(q27) in prepubertal males with the provisional diagnoses of 'developmental delay' and '?XYY'.

The occurrence of the fra(10)(q23) in the pedigree and its resistance to the aging effect which applies to the $\operatorname{fra}(\mathrm{X})(\mathrm{q} 27)$ is of cytogenetic interest. The males carrying both of these sites should yield some interesting observations on the behaviour of the sites during male meiosis if a biopsy can be obtained.

We thank Dr J G Rogers, Dr S Wiener, Professor D M Danks, Jan Schofield, Susan Pavey, and Lynda Green for advice and help. The donation of a photomicroscope by the Fund for Research and Rehabilitation of Retarded Children is gratefully acknowledged.

\section{References}

1 Gerald PS. Editorial. X-linked mental retardation and an X-chromosome marker. $N$ Engl J Med 1980;303:696-7.

2 Turner G, Brookwell R, Daniel A, Selikowitz M, Silibowitz M. Heterozygous expression of X-linked mental retardation and $\mathrm{X}$-chromosome marker fra (X)(q27). N Engl J Med 1980;303:662-4.
3 Sutherland GR, Ashforth PLC. X-linked mental retarda- $\overparen{\mathbb{D}}$ tion with macro-orchidism and the fragile site at Xq27 or 28. Hum Genet $1979 ; 48: 117-20$.

4 Howard-Peebles PN, Stoddard GR. X-linked mental retardation with macro-orchidism and marker $X$ chromosomes. Hum Genet $1979 ; 50: 247-51$.

5 Turner G, Daniel A, Frost M. X-linked mental retarda- $\overline{\bar{D}}$ tion, macro-orchidism and the Xq27 fragile site. $J$ Pediatr $\mathbb{\mathbb { D }}$ 1980;96:837-41.

6 Sutherland GR, Judge CG, Wiener S. Familial X-linked के mental retardation with an $\mathrm{X}$ chromosome abnormality $\vec{\circ}$ and macro-orchidism. J Med Genet 1980;17:73-4.

7 Jacobs PA, Mayer M, Rudak E, et al. More on marker X $\overrightarrow{\vec{\omega}}$ chromosomes, mental retardation and macro-orchidism. $N$ Engl J Med 1979;300:737-8.

8 World Health Organization. International Classification of Impairments, Disabilities, and Handicaps. Geneva: WHO, 1980:53.

9 Sutherland GR. Heritable fragile sites on human chromosomes. 1. Factors affecting expression in lympho- $\vec{A}$ cyte culture. Am J Hum Genet 1979;31:125-35.

10 Leversha M, Webb GC, Pavey SM. Chromosome banding required for studies on $\mathrm{X}$-linked mental retardation. Lancet $1981 ; \mathbf{i}: 49$.

11 Cantu JM, Scaglia HE, Medina M, et al. Inherited congenital normofunctional testicular hyperplasia and mental deficiency. Hum Genet 1976;33:23-33.

12 Harvey J, Judge C, Wiener S. Familial X-linked mental retardation with an X chromosome abnormality. $J$ Med $\underset{N}{\infty}$
Genet $1977 ; 14: 46-50$.

13 Bowen P, Biederman B, Swallow KA. The X-linked syndrome of macro-orchidism and mental retardation: further observations. Am J Med Genet 1978;2:409-14.

14 Turner G, Eastman C, Casey J, McLeay A, Procopis P, $\bar{O}$ Turner B. X-linked mental retardation associated with macro-orchidism. J Med Genet 1975;12:367-71.

15 Hecht F, Kaiser-McCaw B. Editorial. The importance of being a fragile site. Am J Hum Genet 1979;31:223-5.

Requests for reprints to Dr G C Webb, Genetics Research Unit, Royal Children's Hospital, Parkville, Victoria 3052, Australia. 